\title{
Science and national development in Sri Lanka: vision and reality
}

\author{
S N Arseculeratne \\ Department of Microbiology, Faculty of Medicine, University of Peradeniya, Peradeniya
}

\begin{abstract}
Modern science and its derivative technology are essential for national development as seen in major countries of what is called the "Developing World", such as India and China. It is argued that these countries which did not partake of the Western scientific revolution, need specific policies for the growth of science and technology as bases for the planning and implementation of developmental programmes. This paper begins with statements on the history of modern science, types of science and scientific literacy. The critical areas that are identified are scientific research, research funding, science education, and the establishment of a scientific culture in the country and the state of scientific literacy in both the citizens and the elite who aspire to be practising scientists. Psychological and socio-cultural differences between eastern and western countries are identified as determinants of the status of scientific development in these countries.
\end{abstract}

Keywords: national development, scientific literacy, science administration, policies for science

\section{INTRODUCTION}

Jawaharlal Nehru, the remarkable Prime Minister of India in the late 1950s, initiated the development of science in India with his famous speech to the Indian parliament in which he said: "I see no way out of our vicious circle of poverty except through the means that science has placed at our disposal". Remember that Nehru, did his natural science tripos in Cambridge, but Sri Lanka did not have the advantage of such a leader. Nehru set up the Indian Institutes of Technology and the Indian Institutes of Science, formulated the first Indian National Science Policy of 1958, and now India and China are fast developing economic powers; Indian technology is now exported as railway engines to African states, motor vehicles to several neighbouring countries including Sri Lanka and their space exploration and nuclear power programmes are expanded. However, short-falls in translation of science and technology (S\&T) to Indian society are all-too visible, there are still unacceptable levels of illiteracy, poverty and disease. In our adaptation or translation and implementation of policies for science and technology for development in Sri Lanka, we should be aware of the problems of our neighbour, India.

\section{What is Science?}

Very briefly science is the systematic, dispassionate exploration of nature. There is modern science, which was established through the Scientific Revolution in Western Europe during the last 3 or 4 centuries. Its arrival in Asian countries was through colonialism. There was science in the ancient and mediaeval Indian, Chinese and Arabic civilizations which contributed roots to the growth of modern science, but it did not grow autonomously into a modern science. There are the abstract sciences, mathematics and theoretical physics, fields in which Indian excellence is visible, natural sciences, physical sciences, biological sciences and the social sciences, sociology, anthropology, economics and political science.

\section{What is scientific literacy?}

What a proper science education should succeed in establishing is (i) an awareness of the history of the growth of science, (ii) the content of modern science, (iii) appreciation of a scientific attitude, (iv) the methodologies of science, and ( $\mathrm{v}$ ) the interactions between science, scientists and government (Arseculeratne, 1997).

There are several different types of science and scientific research. There is 'pure science', which may be thought of as a body of knowledge which has been accumulated through a dispassionate inquiry into nature for its own 
intellectual sake, and a key phrase is, without the prospect of immediate application. Huxley (1934) subdivided basic research into 'background research' which has no practical objective and 'basic research' which has some distant practical objective. Others called the latter 'oriented basic research'. 'Applied scientific research' implies a conscious orientation or a need-oriented activity which results in the solution of practical problems which are concerned with daily life at one extreme and with national development on a broader scale. Other terms are 'adaptive research', 'developmental research' which are self-explanatory. There is 'subsistence science', e.g. production of medical graduates, and 'innovative science' for development. Reductionism is a characteristic of the practice of the hard, and especially the natural sciences, to delve deeply into the fundamentals. But this specialization has bred the two cultures, "the arts and the humanities' and the 'Sciences', with an arbitrary division between the two, especially after the $18^{\text {th }}$ century.

Next, the inter-relationships between basic or fundamental and applied research is considered briefly. To a practising scientist, these are complementary aspects of the applicability or utilitarian functions of science. As Levy (1934) wrote: 'surely they are interdependent and they differ only in their remoteness from application'. But scientifically illiterate people, both so-called scientists and politicians often regard basic research as a dispensable luxury. It is worthwhile recalling what the US biochemist Arthur Kornberg said (1954): 'Were there an intentional effort to undermine the health and economic welfare of this country for coming generations, I could imagine nothing more devastating than to stop training our best young people to do research in basic medical science'.

If that is true for the United States, how much more devastating it would be for us? Basic science would not only refer to the technical basis of science in practice, but as importantly to the understanding of what science is and its philosophy. If a scientist from probably the most prestigious medical-science institute in a neighbouring country concluded from his/her 'research' findings that the infective disease known for 118 years as rhinosporidiosis caused by a soil-water based micro-organism, is not an infection at all but its appearances in diseased tissue are really due to excessive consumption of tapioca starch, such a distortion would arise from an ignorance of the philosophy of science, especially the ideas of causality, and the absence of the logic of scientific inference.

\section{THE GROWTH OF MODERN SCIENCE}

Ancient science was practised in Indian, Chinese and Arabic civilizations; it was essentially utilitarian in orientation. Arunachalam (1986) reminded that ancient ayurveda had orientations similar to those of modern scientific research, but unfortunately they did not grow into what can be compared with modern science. Various theories have been proposed - Merton's, Zilsel's, Hessen's, Needham's (Bynum et al., 1983) - that explain the social determinants of the growth of modern science.

The British established a few research institutes such as the TRI, RRI and CRI for their economic interests in Ceylon. These colonialists used science for its utilitarian values while we failed to imbibe its nomothetic bases. The British established universities, on their own models, in Colombo, Hong Kong, Delhi, Kuala Lumpur; their functions were (i) the establishment of a scientific culture, (ii) professional training, (iii) creation of new knowledge and (iv) dissemination of knowledge.

\section{THE MODERN CONCEPT OF POLICIES FOR SCIENCE, AND THE PLANNING FOR SCIENCE}

There is a need for a policy for science (not a science policy) in countries that did not participate in the growth of modern science, "In these countries, science is not a part of their culture as much as ours in a premodern scientific one. It is not surprising therefore when Moravscik from the US said here at a seminar in 1976, that the US never had a science policy" (Arseculeratne, 1980). The National Science and Technology Policy drafted by the Science Policy Research Committee of the National Science Council in 1978, is the first Cabinet approved policy statement on S\&T, and the far-sighted scientists who in the late 1950s and early 1960s have established the National Science Council must be thanked. A history of planning for science is given by M.A.T. de Silva and briefly in the essay 'Recollections on the National Science Council (NSC)', 1977 - 1980 when it became NARESA.

Points from the policy statement that are relevant to the discussion. There are two points that need quoting:-

12. ...utilise traditional knowledge, where relevant, for national programmes based on science \& technology

13. ...preferentially use, where relevant, indigenous material and human resources, in the pursuit and application of scientific research.

'...In the early 1980s, the government reconstituted the NSC, against the wishes of the scientific community, as the Natural Resources, 
Energy and Science Authority (NARESA). In the process the government dismantled the statutory working committee on Science Policy Research' (Amaradasa \& de Silva, 2001).

The final death-blow to science in Sri Lanka was thereby the abandonment of the programme for the implementation of that policy. Since then the wheel was re-invented with yet another Science Policy; that is now becoming a fruitless habit.

\section{SCIENCE AND TECHNOLOGY (S\&T) IN NATIONAL DEVELOPMENT}

There are three comments that must be made -

(i) Huxley's view from Britain in 1934: 'I became more than ever impressed with the fact that both our existing structure of civilization and our hope of progress are based on science and that the lack of appreciation and understanding of science among businessmen, financiers, educational authorities, politicians and administrators, was a serious feature in our present situation'. That was in Britain in 1934, whereas Sri Lanka in 2010 are as much in the same situation.

(ii) the famous statement of Nehru that was quoted at the beginning, and

(iii) the basis of the link between S\&T and development, should be based on- '...the ethos of modern science and its interaction with traditional \& culture'.

The baselines are as follows-

i. Short-falls in development (Arseculeratne, 1980), morbidity and mortality from preventable diseases (e.g. $18 \%$ out of $80 \%$ of our (rural) population has no suitable potable water), insufficient agricultural and industrial productivity, excessive population growth

ii. Desirable and feasible goals of scientific development, spectrum between poor countries (needs, literacy, resources, by-products \& waste, ecology \& environment, health problems)

iii.Limited resources, therefore Technology for what? Not What Technology?

iv. Self-reliance - the endogenous capability for decision making, i.e. identification, analysis and management of scientific \& technological problems. (capability, should be taken to mean, the availability of requirements, sane and scientific judgement and motivation).

v. Modern science \& technology 'cannot be transposed directly from the developed world, and utilized effectively, without our receptivity to our traditions and life styles' (2) .... 'the imposition of inappropriate alien standards and attitudes on traditional cultures and value systems leading to social 'dualism' in the recipient countries, the disintegration of rural societies and the middle class, the establishment of enclaves of foreign economies' (neocolonialism) 'and the inhibition of endogenous scientific and technological growth and capabilities' (Arsecularatne, 1979).

These considerations recall what was written by Arsecularatne (1981) in an unpublished document for the Theme Seminar of the Sri Lanka Association for the Advancement of Science where two viewpoints were considered, (i) that this country has very limited financial and manpower inputs into science and technology and (ii) that development means an increase in the standard of our living in respect of health and nutrition, employment and education, agricultural and industrial productivity, and in a nutshell, those attributes which are reflected in the 'Physical Quality of Life Index'; there is also another index recently invented by the Bhutanese - the 'Happiness Index'.

\section{RESEARCH METHODOLOGY IN SCIENCE, AND UNDERSTANDING SCIENCE}

It has been repeatedly stated that effective research cannot be done except on a sound foundation of understanding what science is, i.e. the philosophy of science. There are examples of ignorance of what science is, that is scientific illiteracy even amongst academics. It is equally disappointing that except during the great days of the late Prof. K.N. Seneviratne, any attempts to educate students on the philosophy of modern science have been seldom. Instead, numerous workshops are held on the writing of scientific papers which is putting the cart before the horse, or as Mr W.J.M. Lokubandara, the interesting and witty minister said; "we Sri Lankans first put on our shoes and then the socks".

\section{FUNDING}

It is sometimes stated that Sri Lanka has a lower input, less than $0.2 \%$ quoted as percentages of GDP (or GNP), in $\mathrm{R} \& \mathrm{D}$ than the technologically developed countries (TDC) that have $2-4 \%$. 'These indices might not always be valid and it is considered that what matters more is where and into what targets the financial inputs are made, and whether there are devices and strategies for the monitoring of the use of such inputs' (Arsecularatne, 2008). They do not indicate the distribution and utilisation of the investments; proper science education and 
scientific manpower in research promotion are not easily quantified. R \& D input data in technologically developed countries include inputs into high-cost projects such as space travel, nuclear technology and defense, and are not relevant to poor countries that have many more urgent problems to deal with. These views imply the importance of the determination of priorities. Space exploration is now popular in India (although there is much illiteracy, poverty and disease), nuclear technology is probably a priority in India, China and North Korea. Hence their inputs into such research and technologies should not guide us in the apportioning of the scarce resources.

The factors that would determine priorities in funding would be the availability of resources e.g. resources, social needs, literacy-status (scientific and alphabetic), and the need for a balance between basic and applied research (WHO/SEARO, 1982).

\section{EDUCATION IN SCIENCE}

It is fairly obvious that we have failed to implement, the functions of a modern university on the British model. This is not to hold an exclusive brief for the British system; it was a historical accident, and now there are several more examples elsewhere to derive inspiration from. But it can be claimed that institutions must be devised relevant to Sri Lankan context. The underpinnings of what that means involves the social and cultural relevance of science and science-based technology. The basic premise in the essay by Arsecularatne (1999) is that modern science is alien to our culture and that efforts must be made to circumscribe education and the practice of science in cultural terms. Something similar was said by Ziman (1969) in his Rutherford Memorial Lecture to the Royal Society of London, 'Science education in schools (of developing countries) is of critical importance; ...research could never thrive there without a complete psychological reorientation'. To give you some idea of the falling status of Sri Lanka's educational standing,

(i) in the $1950 \mathrm{~s}$ and $60 \mathrm{~s}$, Sri Lankan students, but not the students from other Asian countries, Canada or Australia were exempt from qualifying examinations before they proceeded to a $\mathrm{PhD}$ in Cambridge, emphasizing the excellence of their background.

(ii) Then a quote from The Island (28 March 2008, p. 11) 'By the late 1972, there were signs of an emerging educational crisis. The signs of potential crisis included the escalation of declining quality, doubts about the relevance of curricula imported from the West, New Mathematics and Integrated Science from Britain, Social Science from America, Pre-vocational education from East Germany'. As pointed out, this attitude of borrowing contradicts the policy of self-reliance in the S\&T national policy of 1978.

(iii) Presently only the University of Colombo, at the $78^{\text {th }}$ place, is included in the rankings of Asian universities.

As much as self-reliance was stressed, the writer disagrees with Dedijer (1963), who prescribed links with the technologically developed countries for international collaboration; the preference for regional collaboration depended on (i) relevance and sharing of problems involved in development, (ii) similarities of administration given our colonial history, (ii) financial considerations in training and residence. A most prolific writer on science in India, Rahman (1974) of the CSIR, wrote: 'There is a shift away from the practice of building institutions in the image of institutions of teaching and research of the developed countries. It is now being increasingly realized that the institutions to be established are to be in consonance with the tasks they have to perform and that their excellence is not an abstract quantity; it has to be evaluated in terms of the role they play in the context of the social situation and the attainment of the goals set before them'. In terms of relevance and the social situation, it must be remembered, the first seminar of the Institute of Fundamental Studies was held in the early 1980 s on the origins of life in the universe!

To press on with the topic of relevance and progress in science in Sri Lanka, the question of publications accruing from scientific research must be considered. Sri Lankans have for too-long been fixated on western journals. As the editorial of the 130 year old Indian Journal of Medical Research (Satyanarayana, 2004) stated, it is time to publish in India, meaning, that all attempts must be made to improve the local journals; the reasons are obvious, dissemination of new knowledge on local problems, promoting scientific research, apart from saving of high costs. Another disease that authors in our countries have is Impactitis, excessive attention to Impact Factors in western journals (Satyanarayana, 2008). This is clearly a vicious cycle and local authors and editors of local journals should make amends to break that cycle.

\section{THE SCIENTIFIC ATTITUDE (THE SCIENTIFIC TEMPER - NEHRU), ETHOS IN SCIENCE}

There are important differences between the East and West in modes of thinking (Arsecularatne, 1980; 1995). It was interesting to see that Nakamura (1997) had similar views discussing India, China, Tibet and Japan. 
It underscores that the problems of the application of science in development are based on psychological and cultural factors and not on economic ones.

It appears that the efforts to establish a scientific attitude and an effective practice of science in this country were bedevilled by the historical reason that the revolution in modern science that occurred in western Europe accompanied by the renaissance had no direct involvement of South Asia (Arseculeratne, 1999). A component of this situation was the absence of what may be called the scientific attitude that underlay the rapid progress of science in the West. However, the development on the other hand, of philosophical thought in Asia needs to be recognized, while also remembering the contributions by ancient Indians such as Bhaskara and Aryabhatha who contributed to the roots of modern science. In other words, to use the phrases of Nakamura (1997) what contrasted Asia and the East from the West were the 'ways of thinking' that are indispensable for the pursuit of modern science. Given below are extracts (paged) from Nakamura's book (1997) that illustrate the different modes of thinking:

In these cases (codes of the Jains, Upanishads, and early Buddhist texts) there is a sharp distinction between the one who teaches and the one who receives the teachings. The lessons are always one-sided; the teacher taught and the followers accepted his instructions with unthinking obedience. And at this stage there is hardly any interchange of ideas between the two sides'. p. 150.

'In early Indian science, there was a remarkable degree of knowledge of the structure of the human body, chemistry, mathematics, astronomy, chemistry stimulated by the Greek sciences. 'But the Indians ended by adopting and imitating the science of the Greeks, and there was no further development of their own in most sciences. The scientific approach to problems failed to develop in this country where thinking was much more metaphysical'. p. 148.

'As G. Misch pointed out, Indian philosophy is metaphysical in marked contrast to the Greek geometrical view of the physical world'. p. 148.

'Western metaphysics is, or was at least up to the eighteenth century, the study of or into the ultimate principles of 'being'. Thus, metaphysics established its own field of study clearly distinguished from that of natural science. Most thinkers in India, however, did not and do not consider metaphysics in contradistinction to physical science. The goal of Indian philosophy (darsana) is to seek the ultimate principles of universal nature, and therefore, traditional Indian philosophers do not take to a positivistic philosophy of natural science'. p. 148.

'They had no idea of natural science as unique and independent of other fields of study... But no endeavour was made to establish natural science as a separate field of study'. p. 149.

'The dominant philosophical schools of ancient India did not find truth in the agreement of subjective knowledge with the objective order, nor in inter-subjectively valid knowledge, but rather, they sought truth in the practice of ethics, that is in the observance of the rules of conduct'.

'In India, studies of the natural world remained underdeveloped'. p. 147.

'Most Indians have been much more interested in religion and poetry than in historical documentation'. p. 146.

'Furthermore, to givefull play to theirimagination, they exaggerate figures astronomically, and stretch the truth with their magnificent and brilliant style of hyperbole. Like many of their sculptures, their historical works are far from reality, but are rather the products of fantasy'. p. 145.

'Indians, on the contrary, have produced an abundance of myths, but their documents of history are quite few in number'. p.143.

'Indians' love of fantasy also checked the development of natural science in India'. p. 138.

'They respond immediately to all the impulses or impressions, real or illusory, brought on from the outer world, and create fantasies one after another'. p.138.

'There is a tendency among the Indians, divested in general of the concept of a perceptible order, not to differentiate too sharply between the actual and the ideal or between fact and imagination or fantasy'. p. 136.

'In their clear expression of order in the objective world by linguistic form, modern Western languages are far more developed than Sanskri and classical western languages'. p. 136. 
'The Indian tendency to alienate the objective natural world and to live in the world of meditation also characterizes Indian art'. p. 36.

'Thus, having no liking for summarising or making rules of phenomena from a recognition of some order among them, Indians used frequent repetition'. p. 133.

'In comparison with westerners who make classifications of various phenomena according to their importance, Indians describe them exhaustively but without order'. p. 132.

'Again due to their way of thinking, which did not distinguish clear and direct perceptions obtained through the sense organs from knowledge obtained through fantasy or inference, Indians were poor in expressions cognizing order among phenomena'. p. 132.

'... we may find that the Indians tended to be lacking in their sense of order in the natural world'. p. 132.

\section{THE SOCIAL RELEVANCE AND CONTEXT OF SCIENCE}

'Science is public' meaning that the methods and results reflect some degree of objectivity, making possible reinvestigation by other workers for verification or better falsification. The social content-context of some areas of applied science and in the social sciences, is less-well defined and this is more so in the East; for example, the social acceptability of family-planning practices. In other areas, that can be called extrinsic, there is less of a difference between the hard or natural sciences and the social sciences, for example relations with society, interactions with the state/administrators, other disciplines, funding.

Finally, to compare research policies for the social sciences with those for the natural sciences in terms of the indispensable and dispensable or inapplicable components of the scientific enterprise. A paradigm of the humanities in which the social sciences are included, the paranormal or parapsychology which has earned sufficient credibility over the last 100 years will be used, to enter serious discussions in the West. Stevenson (1999) considered the following items of conventional scientific exploration to be 'inessential', (and it could be added, 'inapplicable'), in parapsychological research: 1. repeatability, 2. use of controlled conditions, 3. falsifiability, 4. predictive capacity, 5. quantification (with a qualification given below).
The following questions can be asked-

1. If statistical or mathematical methods are used in the natural sciences what is their place in the social sciences?

2. Observer effects are postulated for research in parapsychology. Do they occur in social science research? With the hard sciences it is probable that experimenter effects do not occur, except with faulty methods through ignorance on the part of the experimenter.

3. Controls are vital in natural science research; have they a place in social science research?

4. When dealing with deterministic causality in the hard sciences, logical inference from data is possible, but as Schaffner (1983) stated: 'In the biomedical sciences probabilistic causality may be found in genetics, evolutionary theory, and epidemiology. In so far as events are not completely determined by known causes in complex physiological systems' (and here could be added, probably in the social sciences), 'an important residuum of stochasticity enters'.

\section{SUMMARY OF DISCUSSION ON SCIENTIFIC RESEARCH}

In summary, generally speaking, research in the hard and natural sciences differs from that in the social sciences (sociology, anthropology, economics, ethics, political science) in some respects:-

i. Verifiablity (or falsifiability) and reproducibility characterize hard and natural sciences, but not social sciences where conditions are not replicable.

ii. The resource material in hard and natural sciences is tangible but not in social sciences.

iii The measuring instruments differ, well defined, objective physical methods in hard and natural sciences, and subjective, experimenter-dependent methods in social sciences.

iv. These differences result in differences in data obtained and in analysis.

v. Hard and natural sciences is experimental / heuristic with controllable variables while social sciences is more descriptive, observational, and comparative where the variables are not controllable.

vi. Ethical issues predominate in social sciences.

vii. Experimenter or observer-dependent effects predominate in social sciences.

viii. Social sciences are not amenable to hard-andfast rules where complex interacting factors predominate.

ix. The predictive power of hard and natural sciences theories is greater than in the social sciences where probabilities are more in effect. 
Similarities include

i. the formulation of hypotheses for testing.

ii. Mathematical/statistical treatment of project planning and of data occur in both but are probably more difficult in the social sciences.

\section{CONCLUSION}

Four points for the attention of those who will draft a policy for research in science can be considered:-

1. What has been stated above is mostly a vision. The reality of Sri Lankan preparedness must be taken into account in drafting policies and instruments for their implementation in Sri Lanka.

2. The goals of science education and science research should aim at producing a scientific elite, not just once but continuously, while promoting scientific literacy in the general population.

3. Priorities in terms of Sri Lanka's needs and resources have to be considered, at all levels, in the planning and implementation of policies for science (hard and natural sciences and social sciences).

4. These are personal views of the writer and merely guidelines for drafting of policies. A separate policy or program for their implementation would be desirable.

\section{ACKNOWLEDGEMENT}

Prof. Gerald Peiris and Dr Sisira Dharmaratne are thanked for discussions on research in the social sciences.

\section{References}

1. Amaradasa, R. M. W. \& de Silva, M.A.T., 2001. The evolution and structure of Science and Technology in Sri Lanka. Science, Technology \& Society. 6(1), pp. 179-201.

2. Arseculeratne, S. N., 1979. 'Scientific research for development. Viewpoints from the developing world'. Paper presented at the UNCSTD conference, Bangalore.

3. Arseculeratne, S. N., 1980. 'The basis of our self-reliance in science \& technology'. unpublished document for the Theme Seminar, SLAAS.

4. Arseculeratne, S. N., 1997. Science \& technology education in Sri Lanka: Concepts and problems In: Edgar W. Jenkins, ed. Innovations in Science \& Technology Education. Paris: UNESCO.

5. Arseculeratne, S. N., 1999. The determinants of the growth of science in pre-modern South Asia. Felicitation volume in honour of Professor K. M. de Silva. Colombo: ICES.

6. Arseculeratne, S. N., 2008. 'A National Policy for the Promotion of Scientific Research'. Paper presented to the Board of Management meeting of the National Science Foundation, Colombo, April.

7. Arunachalam, S., 1986. Methodology in Ayurveda to steer research in Ayurveda. In: Ayurveda Sameeksha. Vol. 1, part 2, pp. 301-10.

8. Bynum, W. F., Browne E. J. \& Porter R. eds., 1983. Dictionary of the History of Science. London: Macmillan Press.

9. Dedijer, S.,1963, Underdeveloped science in underdeveloped countries. Minerva, 11, pp. 61-81.

10. Huxley, J., 1934. Scientific Research and Social Needs. London: Watts \& Co.

11. Kornberg, A., 1973. The support of Science. Editorial. Science, 180, pp. 4089.

12. Levy H., 1934. Foreward. In: Scientific Research and Social Needs. London: Huxley, Julian, Watts \& Co.

13. Nakamura, H., 1997. Ways of thinking of Eastern people: India, China, Tibet, Japan. London: Kegan Paul International.

14. Rahman, A., 1974. Problems of planning of Scientific Research in Developing Countries. Journal of Scientific \& Industrial Research, 33(6), pp. 273-75.

15. Satyanarayana, K., 2004. Editorial. Time to Publish in India movement. Indian Journal of Medical Research, 119, pp. vii-ix.

16. Satyanarayana, K. \& Sharma, A., 2008. Editorial. Impact factor; time to move on. Indian Journal of Medical Research, 127, pp. 4-6.

17. Schaffner, K.F., 1983. Explanation and causation in the biomedical sciences. In: L. Laudan ed. Mind and medicine: problems of explanation and evaluation in psychiatry and the biomedical sciences. $3^{\text {rd }}$ ed. Berkeley: University of California Press.

18. Stevenson, I., 1999. What are the irreducible components of the scientific enterprise? Journal of Scientific Exploration, 13(2), pp. $257-70$. 
19.WHO/SEARO, 1982. Implications for Member Countries of the varying emphasis given to various types of research including basic research. In: Working Group Meeting. Bali, 9-13 August (The Bali document).
20.Ziman, J.M., 1969. Some problems of the growth and spread of science into developing countries: The Rutherford Memorial Lecture, In: Proceeding of the Royal Society, London 311, pp. 349-69. 